\title{
Left ventricular assist device therapy in a patient with hearing and speech disabilities
}

\author{
From the Department of Cardiac Surgery, Medical University Graz, Graz, Austria. \\ Disclosures: Authors have nothing to disclose with regard to commercial support. \\ Received for publication March 9, 2018; revisions received May 6, 2018; accepted for publication May 14, 2018; \\ available ahead of print June 27, 2018. \\ Address for reprints: Sotirios Spiliopoulos, MD, PhD, Department of Cardiac Surgery, Medical University of \\ Graz, Auenbruggerplatz 29, 8036 Graz, Austria (E-mail: sp11@outlook.de) \\ J Thorac Cardiovasc Surg 2019;157:e1-2 \\ $0022-5223 / \$ 36.00$ \\ Copyright (C) 2018 by The American Association for Thoracic Surgery \\ https://doi.org/10.1016/j.jtcvs.2018.05.048
}

Patients with hearing and speech disabilities who are in endstage heart failure are still frequently excluded from left ventricular assist device (LVAD) therapy because of safety concerns. LVAD therapy for these patients is feasible; however, it requires both technical fixes and establishment of a social and medical safety net. We report the successful implementation of LVAD therapy in a 74-year-old patient with hearing and speech disabilities and describe the technical and social aspects of his care.

\section{CLINICAL SUMMARY}

A 74-year-old, white male patient with hearing and speech disabilities and a history of recurrent cardiac decompensation (functional New York Heart Association class 3b, Interagency Registry for Mechanically Assisted Circulatory Support level 4) was admitted for evaluation of end-stage heart failure resulting from ischemic cardiomyopathy. Echocardiography documented severely compromised left ventricular function (left ventricular ejection fraction, $28 \%$; left ventricular end-diastolic diameter, $80 \mathrm{~mm}$ ), severe functional mitral valve regurgitation (effective regurgitant orifice, $0.4 \mathrm{~cm}^{2}$; vena contracta, $0.8 \mathrm{~cm}$; regurgitant volume, $84 \mathrm{~mL}$ ), reserved right ventricular function (tricuspid annular plane systolic excursion, $26 \mathrm{~mm}$ ), and a persistent foramen ovale. The patient and his relatives were informed of the need for an LVAD implant as a destination therapy, as well of the current lack of experience with this therapy in persons with hearing and speech disabilities.

A HeartMate III Device (Abbott Laboratories, Abbott Park, Ill) was implanted conventionally. The persistent foramen ovale was closed directly with a 4-0 polypropylene continuous suture. Because the mitral valve regurgitation resulted solely from annular dilation, we chose not to repair the valve. The postoperative course was uneventful. The patient was weaned from mechanical ventilation on postoperative day 1 and transferred to the normal ward on postoperative day 6. Serial transthoracic echocardiography revealed proper alignment of the inflow cannula and only minor

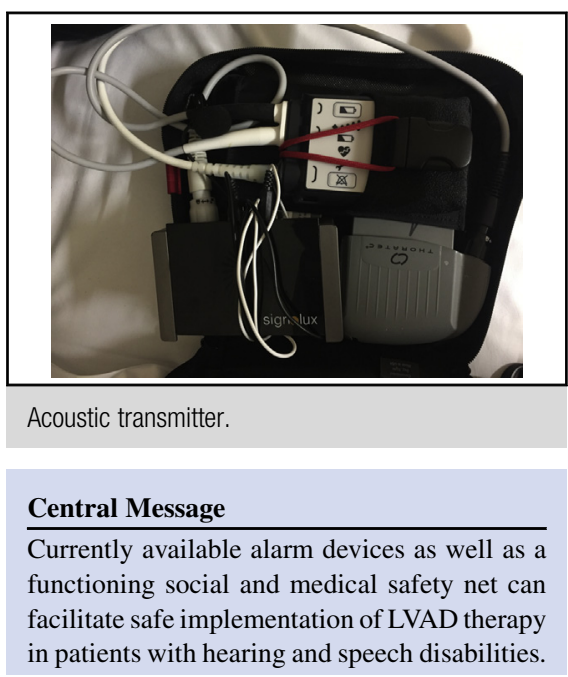

See Editorial Commentary page e3.

regurgitation from the mitral valve. The Signolux system (Humantechnik, Weil am Rhein, Germany) that we used to make controller alarms perceptible for the patient is a commercially available, reliable assistive device commonly used to notify individuals with hearing impairment of everyday emergency situations, and he was already familiar with this system. It consists of a cellular acoustic transmitter with a microphone cable placed in the carrying bag next to the pocket controller that receives and then forwards frequency modulated acoustic signals with a time delay of 1 second from the controller to the receiver, a portable vibrating and blinking-light pager (Figure 1), and a vibrating pillow to alert the patient during the night. An acoustic engineer was consulted before implementation of therapy. Because the acoustic transmitter operates in a significantly lower radio frequency spectrum than the continuous-flow pump, the engineer was able to exclude any risk of interference. The patient's wife and his daughter, who also had hearing disabilities and who lived in the same house, also received vibrating pagers. Each individual controller alarm was programmed in the respective transmitter and made perceptible to the patient and his relatives with different vibration rhythms and colored lights. A sign-language translator assisted during training with the LVAD and the alarm system. The patient was trained to react to vibration and flashing lights by promptly reading texts displayed on the controller interface and then either troubleshooting for 


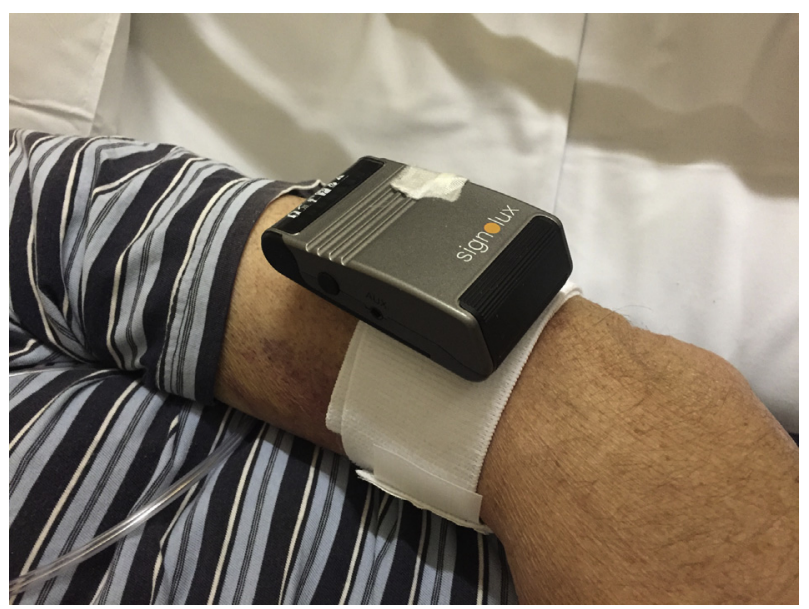

FIGURE 1. A portable pager is used to notify the patient of pump events.

common alarms or contacting our team by short message service (SMS) text in emergencies. Because remote monitoring was not an option, the patient was requested to record alarm events and report them daily by SMS text. LVAD competence was tested before discharge and proved to be equivalent to that of patients without disabilities. The patient was linked to our ambulatory care center for patients with hearing impairment, whose staff were trained to deal with common issues of LVAD therapy. The patient has to date (201 days after surgery) had no adverse events. The alarm system has proved to be reliable, without any signs for interference between the LVAD pump and the transmitter. Three low-battery advisory alarms were recognized and dealt with by the patient himself, without the need for further assistance by his relatives.

\section{DISCUSSION}

Patients with hearing and speech disabilities who have end-stage heart failure are still excluded from LVAD therapy because of safety concerns related to their presumed inability to respond to advisory and hazard controller alarms. ${ }^{1}$ Successful implementation of LVAD therapy in these patients is feasible, however, provided that the alarm system used functions reliably and that acoustic signal transmission is not compromised by pump operation. Commercially available transmitters operate on a different radio frequency spectrum than continuous-flow assist devices, ${ }^{2,3}$ and signal transmission is therefore not prone to interference. In addition, the patient must be trained to recharge the vibrating pager (every 90 days) and to replace the transmitter batteries (every 100 days). In addition to technical aspects, treatment success depends on the establishment of a social and medical safety net: relatives must be closely involved in the surveillance and maintenance of the alarm as well as the LVAD system, and specialized caregivers must become familiar with the special needs of LVAD recipients.

We acknowledge the valuable linguistic assistance of Ms Eugenia Lamont during revision of the manuscript.

\section{References}

1. Feldman D, Pamboukian SV, Teuteberg JJ, Birks E, Lietz K, Moore SA, et al; International Society for Heart and Lung Transplantation. The 2013 International Society for Heart and Lung Transplantation guidelines for mechanical circulatory support: executive summary. J Heart Lung Transplant. 2013;32:157-87.

2. Hubbert L, Sundbom P, Loebe M, Peterzén B, Granfeldt H, Ahn H. Acoustic analysis of a mechanical circulatory support. Artif Organs. 2014;38:593-8.

3. Shah M, Bull D, Markey P, Chew HC, Cheong C, Robson D, et al. Acoustic characterisation of the HeartWare ventricular assist device as a novel non-invasive diagnostic and management technique. J Heart Lung Transplant. 2017;36(4 Suppl):S351. 